\title{
Study on IGBT Module Aging and Automatic Test Systems
}

\author{
Yaping $\mathrm{Li}^{1 \text {, }}{ }^{2}$, Luowei Zhou* ${ }^{1}$, Xiong $\mathrm{Du}^{1}$, Pengju Sun ${ }^{1}$ andJunke $\mathrm{Wu}^{1}$ \\ ${ }^{1}$ State Key Laboratory of Power Transmission Equipment \& System Security and \\ New Technology Chongqing University, Chongqing 400044, China \\ 2. College of Mechanical and Electronical Engineering, Shihezi University, Shihezi \\ 832000, China \\ liyaping425@163.com
}

\begin{abstract}
A set of accelerated aging and automatic test system for IGBT modules is designed in this paper, including platforms of accelerated aging and parameter automatic test. Aging test platform is controlled by IPC, using DC power cycling methods and water cooling to heat dissipation. Combined with LabVIEW and high-speed digitizers, single pulse switch testing is achieved in automatic test platform through hardware circuit. In different stages of the IGBT module aging tests, change trend of each electrical parameters were measured under different working point. Collector-emitter conduction voltage drop $V_{C E(\text { sat }}$, gate-emitter threshold voltage $V_{G E(t h)}$, turn-off time $t_{\text {off, }}$ the current and voltage waveform during turn-on and turn-off are measured. The relationship between these electrical parameters and aging degree of the IGBT module is researched. It would be able to characterize the device and seek out external indicators of fatigue aging, reliable evidences for state assessment. Compared with the traditional manual testing methods, the automatic test system has characters: high accuracy, test speed, short development cycle and so on.
\end{abstract}

Keywords: IGBT module, Aging failure, Accelerated aging test, Power Cycling, External indicators

\section{Introduction}

Since the 1980s, the insulated gate bipolar transistor (IGBT) has been put on the market, possessed the dual characteristics of the bipolar transistor and MOSFET, Modern IGBTs are featured by numerous merits like high voltage blocking capability, high current conducting capability, low on-state forward voltage drop and fast switching speed, etc. They are widely used in low to medium (even in high power range) power and high frequency applications, not only in industry, but also more widely used in many other power conversion systems such as electric vehicles, new energy power generation, aviation power supply, etc[1-3].

As the widely applications, the IGBTs have faced a growing demand for high reliability. With the increasing of device power density, the current density in power chip and packaging density in power module are also increased. Usually the application environment is harsh and the processed power is fluctuating, which would be result in a greater temperature and temperature gradient. During operation process, IGBT modules were suffered from thermal cycling and power cycling, which produces stress in the wire connection and multilayer structures contact surface, after a very long fatigue damage accumulation, caused the module aging failure. Many research results show that the aging failure of power module is caused by the mismatch of coefficient of thermal expansion (CTE) between the material layers of the multilayer structure module [4]. The failure is mainly started by the aging module package level failure. If it can not be found timely, the failure would be developed into chip-level failure, or even catastrophic failure. Through detecting the changes of the external electrical 
parameters, the failure phenomenon is found as soon as possible, the device is replaced promptly. It would be help to improve whole system reliability.

Power cycling is the most common acceleration test method used in assessing reliability of IGBT modules. The purpose of the power cycling tests is to understand aging and failure mechanisms of IGBT power modules in a short period time, and to detect weak links in the packaging of IGBT modules. The power applied to the device is switched (on and off) so that the temperature in device would be periodic changed. Power cycling tests, which including conduction and switching, are closer to actual operation of the IGBT module. For this reason, power cycling tests are referred to as "active" cycling tests [5]. According to the references [6-8], fast power cycling (time period in the order of tens of seconds) and higher temperature swing $(\Delta T>100 \mathrm{k})$ leads to wire-bond failure, while slow power cycling (time period in the order of minutes) and lower temperature swing $(\triangle T<80 \mathrm{k})$ leads to solder fatigue related failures. Some literatures adopt the way of cutting off bonding wire directly one by one to emulate bond wire lift-off, which is targeted, time saving and changed in the case study of aging indicators under the aging patterns [9-10]. Unfortunately, it does not match the actual aging process. Moreover, most of the literatures about power cycling tests do not express in detail about the dependence of operating conditions, failure criteria/indicators, etc. Hence it is badly in need of standardizing procedures of power cycling with greater details.

The parameters/indicators of failures must be monitored and measured which would be an important aspect in design of power cycling experiments. This can be achieved with the knowledge of failure modes. Some of the common failure indicators are junction temperature, collector-emitter voltage $\left(V_{C E}\right)$,gate threshold voltage, thermal impedance $\left(Z_{t h}\right)$, collector current $\left(I_{C}\right)$, gate current $\left(I_{G}\right)$, drain-source resistance $\left(R_{d s o n}\right)$, turn-off time, voltage ringing[11], and breakdown voltage[12]. The reference [13] presents a measuring method of the collectoremitter voltage $V_{c e}$ detail. Reference [14] presents the failure modes and their indicators in switching power supplies. The choosing criterion of the indicator parameters is based on their dependence on temperature. An indicator of solder cracks is thermal resistance $\left(R_{\mathrm{thjc}}\right)$, while the indicator of wire-bond liftoff is collector-emitter voltage $\left(V_{\mathrm{CE}(\mathrm{sat})}\right)$.

The IGBT module accelerated aging test and automatic test platform are explained detailed in this paper. Furthermore, some useful external indicators of the power module are measured, which is changed before and after aging. The accelerated aging test and automatic test platform this article presented will provide the certain reference foundation to the research of life prediction, condition assessment, failure prognostic of IGBT modules.

\section{IGBT Module Aging and Automaticl Test Platform}

\subsection{IGBT Module and Failure Mechanisms}

Conventional IGBT power modules have a structure of multiple layers. The schematic cross section of a wire-bonded IGBT module is shown in Figure 1. As viewed from the top, the aluminum wires are bonded to the chip top metallization to connect the semiconductor chips, as in the case of IGBTs and FWDs. The silicon chips are soldered onto a DBC substrate, which is soldered onto the baseplate. The IGBT module is encapsulated with silicone gel to increase its physical integrity.

Because the layers of IGBTs are made of materials with different CTEs, a physical departure or crack may be created after undergoing repetitive thermal cycling, power cycling, or mechanical stress during operation. In general, the major failures in standard IGBT modules are: bond wire lift off, heel cracking, aluminum metallization reconstruction, and solder joint fatigue. The aging process of IGBTs will be accelerated after one failure occurred. In turn, the escalated deterioration may trigger other failure models such as open circuits, hot-spots, latch-up, or even burn-outs [15]. 


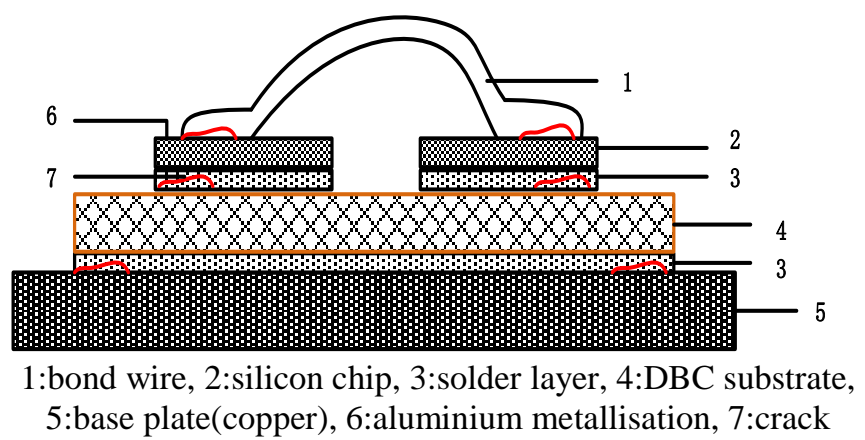

Figure 1. Schematic Cross Section of the IGBT Power Module

\subsection{Design of the Aging Test Platform}

As in the field stress conditions, the reliability test of the power module is obviously impossible, the expected life last 10-30 years. In order to shorten the test research cycle, and improve the efficiency, it is necessary to design an accelerated aging test. In line with the cumulative power cycling of aging process, the module would be aging failure in a short time. The purpose of the test is to estimate the reliability of IGBT modules by a small amount of the sample in a short time. The failure rate of device is quickly predicted by extrapolation method at nominal or actual conditions. According to the results, the aging failure precursor parameters and failure mechanisms of IGBT module are explorated, the failure modes can be exposed in a short time. The assessment of health state of device is conducted, based on failure analysis and precursor parameters to assess its status. The difference between the DC power cycling test and the PWM power cycling test is presented in [16], the DC circuit is simple and easy to monitor parameters. After comprehensive consideration, DC power cycling aging method is conducted in this paper, and the aging IGBT module is Fuji 2MBI75S-120, with 1200 V/75A capacity.

According to IEC60747-9 standard, and to simulate the solder layer and bonding wire fatigue aging of IGBT module, the case temperature and junction temperature need to be fluctuated in a large range, which method is named as $\Delta T_{c}$ power cycling accelerated aging. From the transient thermal resistance curves of the module datasheet, it known that the case to the environment thermal time constant $\tau_{c-a}$ is larger than the junction to the case thermal time constant $\tau_{j-c}$, that means it required to take a long time to make the case heating to the steady state $T_{\mathrm{cmax}}, \Delta T_{j}$ and $\Delta T_{c}$ of the power moduleare are all large in this method, and the aluminum bonding wire and solder layer would be influenced seriously by the temperature fluctuations.

The aging test platform structure is shown in Figure 2 and 3, consisting of IPC, IGBT modules aging testing bench (Figure 2), water cooling system (Figure 3), and programmable DC power supply. 


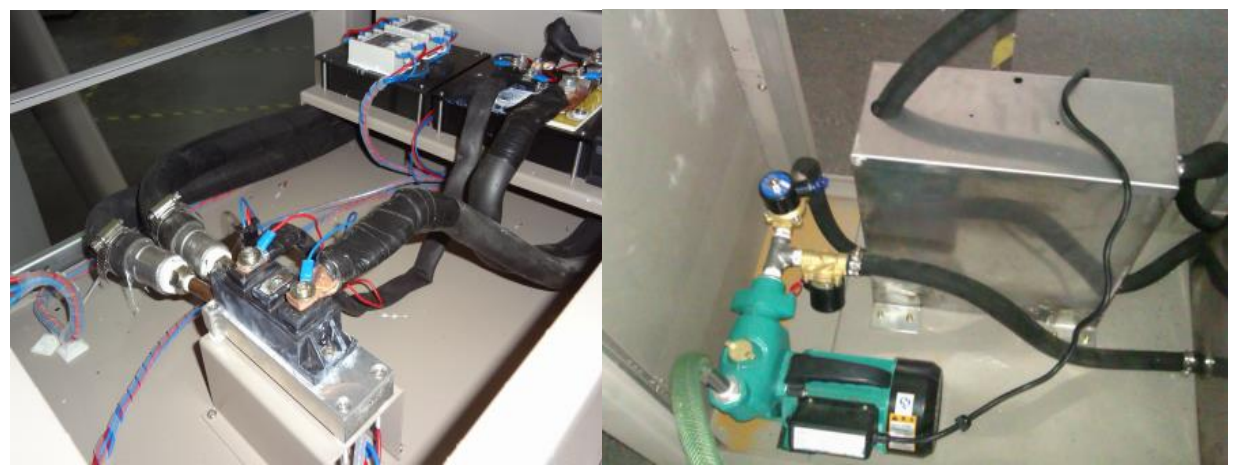

Figure 2. Aging Test Benches Figure 3. Water-Cooling System

The test principle circuit is shown in Figure 4, which is mainly composed of two parts, as power cycling aging part in high-current and junction temperature indirect measurement part in low current respectively.

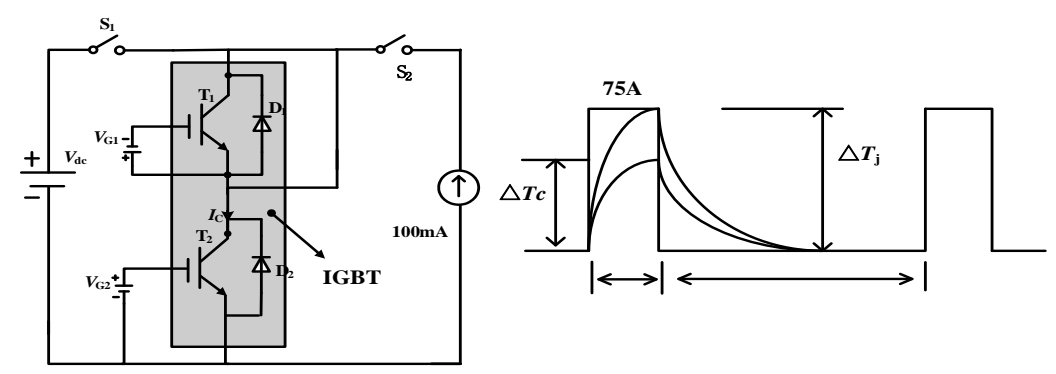

Figure 4. The Principle Diagram of the Aging Test

Editing program on the IPC, the aging process is controlled through the control interface, which can display the aging times, on and off time, voltage drop, the collector current, the junction temperature $\left(T_{j}\right)$ and the csae temperature $\left(T_{c}\right)$.

During testing, Firstly, the parameters setting of aging module are conducted, then location test, click start aging. The switch S1 is turned on, the IGBT modules are injected into the large current $75 \mathrm{~A}$ by programmable DC power supply. It makes the junction temperature rise rapidly on account of producing larger conduction power losses.It lasts about 150 seconds so that the junction temperature rised to $125^{\circ} \mathrm{C}$. Turned off $\mathrm{S} 1$, then turned on $\mathrm{S} 2$, the small current $100 \mathrm{~mA}$ is injected, meanwhile, water-cooling system is started to cool the modules through the heat sink. Combined with junction temperature calibration curve under low current, the junction temperature is obtained indirectly. The junction temperature is droped to $25^{\circ} \mathrm{C}$ for 30 seconds. This is a cycle. The longer Power cycling time means that higher stress of device, and the faster speed of device. The gate electrode of IGBT module is driven by a constant $15 \mathrm{~V}$ and kept open. The test conditions of IGBT module accelerated aging are shown in Table 1.

\section{Table 1. IGBT Module Accelerated Aging Experimental Conditions}

\begin{tabular}{l|l}
\hline Experimental parameter & Parameter values \\
\hline Power-cycling current & $75 \mathrm{~A} \quad$ rated current $)$ \\
Low current for measuring $T_{j}$ & $100 \mathrm{~mA}$ \\
Gate drive voltage & $V_{G E}=15 \mathrm{~V}$ \\
$\Delta T_{j}$ & $100^{\circ} \mathrm{C}$ \\
$\Delta T_{c}$ & $80^{\circ} \mathrm{C}$ \\
\hline
\end{tabular}




\subsection{Design of the Automatic Test System}

There are two kinds of measurement methods for electrical parameters. The one is the online measurement, namely measure in the process of power cycling[17-18]. The other is a static measure, which aslo can be named as measurement in the steady state. The power cycling test is interrupted periodically interruption, electrical parameters are measured and compared from selecting different conditions of the electrical and temperature. The on-line marsurement is difficult to implement, different hardware circuit is needed when measuring different electrical parameters. The design of circuits is complexity. Therefore the static measurement is adopted in this paper. Because the electrical parameters of the IGBT module are mainly affected by the voltage, current and temperature under actual operating conditions.It would be in need of accurate measurement and storage external characteristic parameters under different working conditions. Some appropriate external indicators are selected, which are able to characterize the device fatigue aging degradation.

\subsubsection{Design of the Test System Hardware}

As shown in Figure 5, the automatic test system is mainly composed of the following parts, the computer as the control center of the system, programmable DC power supply is controled by the USB interface, RS232 interface control FPGA, which generates a pulse signal, IGBT module is drived through the optocoupler and driver board, and USB interface control data acquisition devices---digitizer/oscilloscope CL4000, it completes to controlling for each device, data processing and saving through LabVIEW software programming.

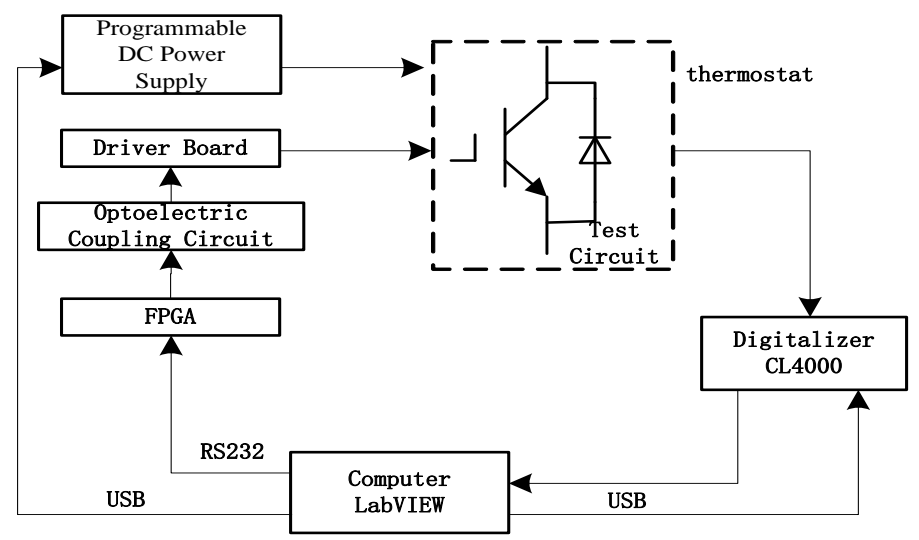

Figure 5. Diagram of the Automatic Test System

Digitizer CL4000, it is a high sampling rate synchronous data acquisition card, and is a modular oscilloscope with a bandwidth of $200 \mathrm{MHz}$, single-channel sampling rate $100 \mathrm{Ms} / \mathrm{s}$, 14-bit high resolution, the maximum input range $\pm 80 \mathrm{~V}$, the minimum input range of $\pm 80 \mathrm{mV}$. Combined with LabVIEW software programming, it is capable of building powerful flexible test system for high-speed data acquisition, high-precision measurements and complex parameter calculations. Automatic test platform is shown in Figure 6. 


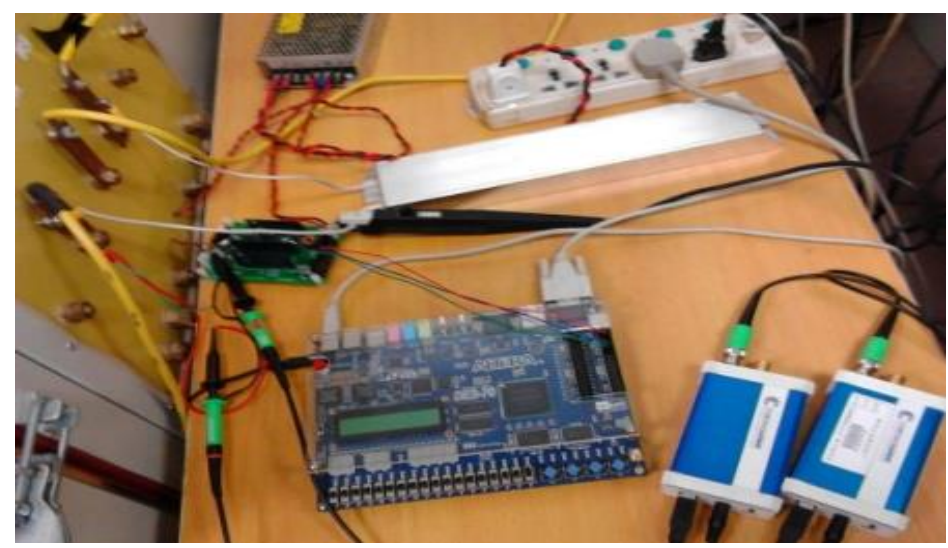

Figure 6. Automatic Test Bench

\subsubsection{Design of Test System Software}

Human-computer interface and automatic test function are realized by LabVIEW software programming. The system software is mainly consisted of instrument control module, data acquisition module, data processing module, data display and storage modules.

LabVIEW software is able to control programmable DC power supply by calling VISA function, complete the collector currents fixed step increase from 1A to 75A. Simultaneously, serial communication between computer and FPGA is realized to control the drive signal. The function modules packaged is called by means of .NET integration technology in LabVIEW directly. The electrical parameters are able to achieve synchronous acquisition, and data is saved as Excel file format automatically, the waveform is saved as TDMS file format for easy analysis at any time to call again. System software flow chart is shown in Figure 7.

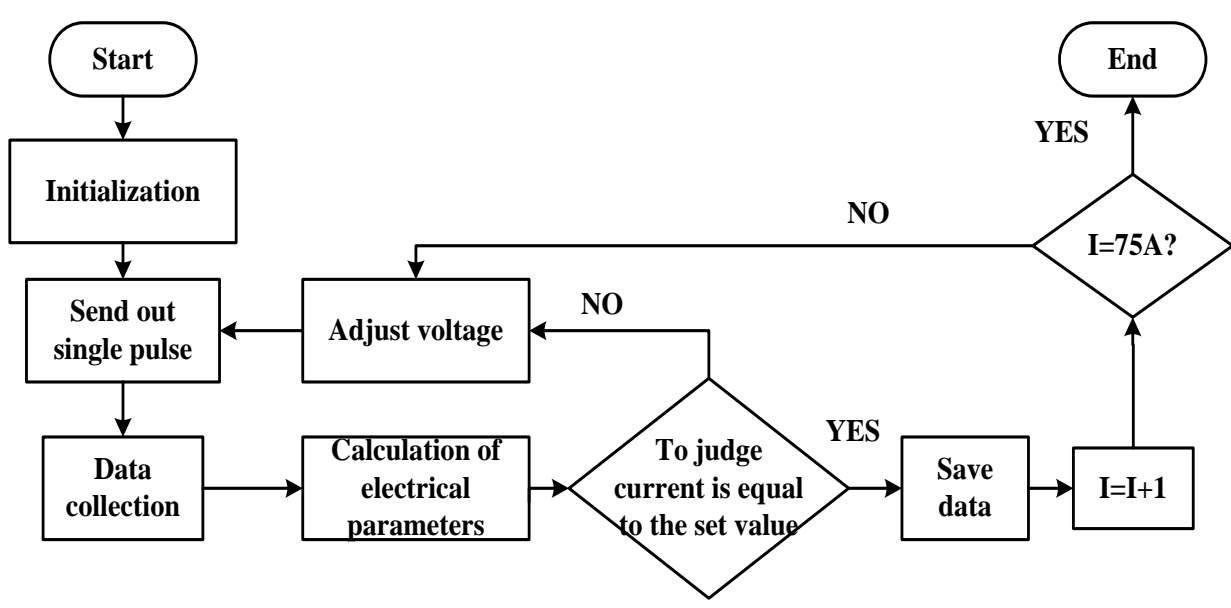

Figure 7. The Flow Chart of System Software

The system is able to implement the variation of the electrical parameters with the different levels of aging under constant temperature, and complete the electrical parameters measurement with different temperature by changing the thermostat temperature.

\section{Analysis of Experimental Results}

Accelerated aging test has been conducted for IGBT module 2MBI75S-120 (1200V/75A). Its aging current is $75 \mathrm{~A}$ which is the rated value of the device.Junction temperature fluctuations $\Delta T_{j}$ is $100^{\circ} \mathrm{C}$, as well as, the case temperature fluctuations $\Delta T_{c}$ is $80^{\circ} \mathrm{C}$. Single pulse testing is conducted to the IGBT module for every aging 1000 cycles. As an example to 
measure $V_{C E(s a t)}$ and $V_{G E(t h)}$, many papers selected these two parameters indicators to investigate aluminum bonding wires off[19] .

As shown in Figure 8, the new module and the module that after aging 8000 cycles is respectively injected $100 \mathrm{~mA}$, the comparison of junction temperature calibration curves are obtained. At low current, $V_{C E(s a t)}$ has a negative temperature coefficient, as the number of aging cycles increase, note that the curve entirety upward shift, but also has good linear relationship. Because of this feature, lots of the literature presented that the juction temperature was indirectly obtained by means of TSEP (temperature sensitive electrical parameter) [20].

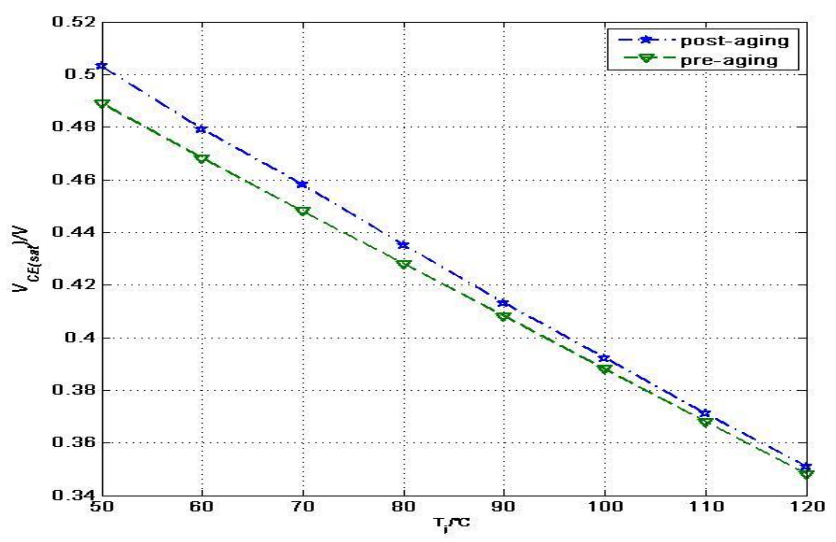

\section{Figure 8. Junction Temperature Calibration Curve under Small Current}

$V_{G E(t h)}$ generally refers to the gate-emitter voltage under a specified collector current and collector-emitter voltage, when the collector current starts to rise during turn-on phase. The gate voltage is measured when $V_{C E}=20 \mathrm{~V}, I_{C}=75 \mathrm{~mA}$ according to the datasheet of the IGBT module, this is the threshold voltage. Shown in Figure 9, $V_{G E(t h)}$ is gradually increased with the aging process. The aging device is mainly due to aging caused by the gate oxide layer, the device is difficult to open, and the junction temperature $T_{j}$ increased, the energy band of the crystal reduced, the carriers are easily excited, and $V_{G E(t h)}$ changed with $T_{j}$ inversely proportional.

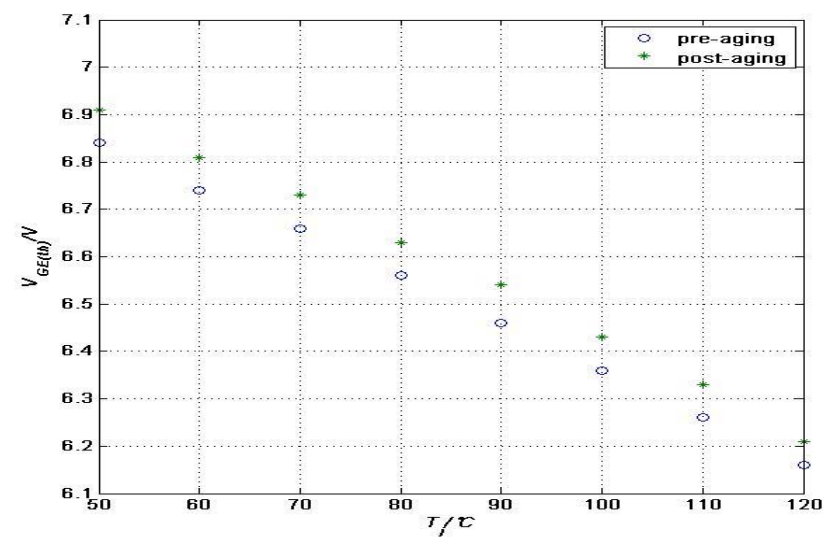

Figure 9. Threshold Voltage Variation at Different Temperatures

The change of $V_{C E(s a t)}$ which is measured every 1000 cycles under different currents and temperatures is shown in Figure 10. With increasing number of power-cycling, it shown that the $V_{C E(s a t)}$ had a gradually increasing trend under the same operating point (i.e., the same 
current and the junction temperature). Figure 11 shown, the crossover current of this IGBT module is approximately 10A, conduction voltage drop shows a positive temperature coefficient above a crossover current, but shows a negative temperature coefficient below it. The literature [18] gave an explanation about it.

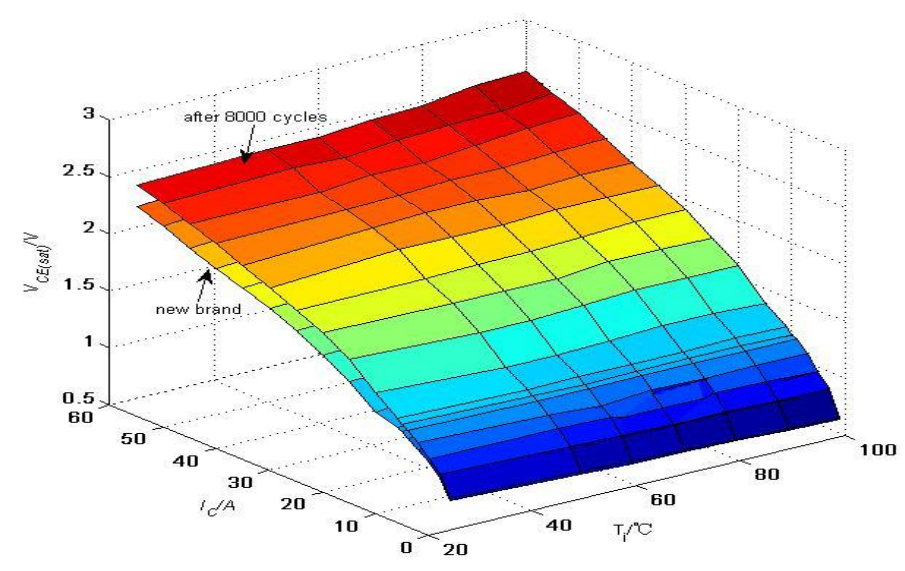

Figure 10. $V_{C E(S a t)}$ Variation Trend In Aging Process

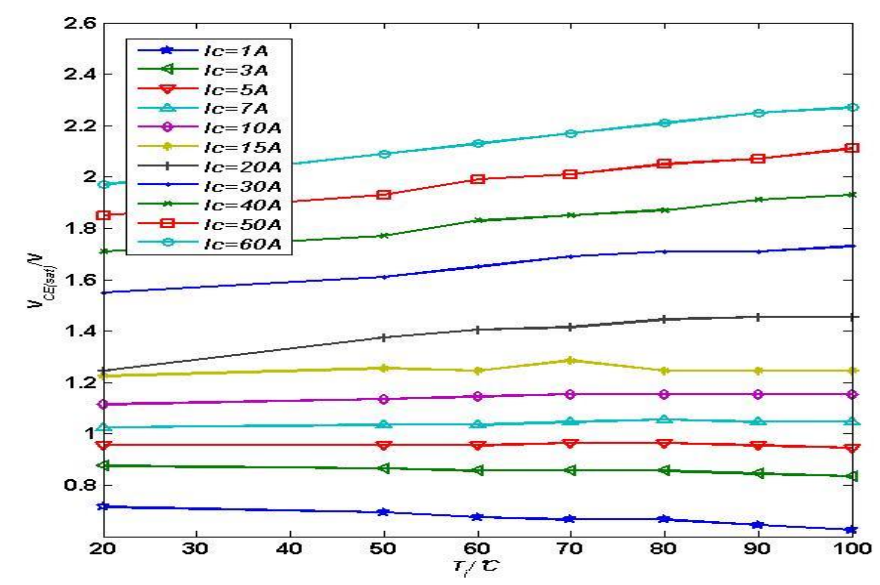

Figure 11. The Curves of $V_{C E(S a t)}=F\left(T_{j}\right)$ With Different Current

\section{Conclusion}

The paper designed the power-cycling aging test system, both the case temperature and the junction temperature has large fluctuations, it speeds up aging in IGBT module. The parameters automatic test system is designed which applied to modular instruments --- highspeed digitizers and LabVIEW software programming, and achieved steady-state and transient parameters of the automatic acquisition. The systems have the characterisc of simple structure, high speed and accuracy. After the IGBT module is aged, on account of performance degradation, the variation trends of each electrical parameters at different current and temperature. With the increasing of the aging number of power-cycling, conduction voltage drop showed a gradually increasing trend under the same operating point (ie, the same junction temperature and current). $V_{G E(t h)}$ is gradually increased with the aging process, also inversely changed with the increase of temperature. This paper aimed to develop an accelerated aging and testing system, and intended to pick out appropriate extranal indicators 
which able to characterize the device fatigue aging, as basic research for life prediction, condition assessment, failure criterion.

\section{Acknowledgement}

This work is supported by The Key project of The National Natural Science Foundation of China, (51137006).

\section{References}

[1] S Yang, A. Bryant, P. Mawby, D.Xiong., L. Ran and P. Tavner, "An industry-based survey of reliability in power electronic converters", Industry Applications, IEEE Transactions on, vol. 47, no. 3, (2011), pp.1441-1451.

[2] J. Ribrant and L. Bertling, "Survey of failures in wind power systems with focus on Swedish wind power plants during 1997-2005”, Power Engineering Society General Meeting, IEEE, (2007), pp $1-8$.

[3] H. Huang and P. A. Mawby, "A lifetime estimation technique for voltage source inverters", Power Electronics, IEEE Transactions on, vol. 28, no. 8, (2013), pp.4113-4119.

[4] S. Yang, D. Xiang, A. Bryant, P. Mawby, L. Ran and P. Tavner, "Condition monitoring for device reliability in power electronic converters : a review. Power Electronics", IEEE Transactions on, vol. 25, no. 11, (2010), pp.2734-2752.

[5] M. Held, P. Jacob, G. Nicoletti, P. Scacco and M. H. Poech, "Fast power cycling test of IGBT modules in traction application", Power Electronics and Drive Systems, 1997 International Conference on. IEEE, (1997), pp.425-430.

[6] B. Ji, V. Pickert, W. Cao and B. Zahawi, "In-Situ Diagnostics and Prognostics of Wire Bonding Faults in IGBT Modules for Electric Vehicle Drives", Power Electronics, IEEE Transactions on, vol. 28, no. 12, (2013), pp.5568-5577.

[7] W. Kexin, D.Mingxing, X. Linlin and L. Jian, "Study of Bonding Wire Failure Effects on External Measurable Signals of IGBT Module", Device and Materials Reliability. IEEE Transactions on, vol. 14, no. 1, (2014), pp.83-89.

[8] S, Zhou, L. Zhou and P. Sun, "Monitoring potential defects in an IGBT module based on dynamic changes of the gate current", Power Electronics, IEEE Transactions on, vol. 28, no. 3, (2013), pp.1479-1487.

[9] M. Mermet-Guyennet, X. Perpiñá and M. Piton, "Revisiting power cycling test for better life-time prediction in traction", Microelectronics Reliability, vol. 47, no. 9, (2007), pp.1690-1695.

[10] R. A. Amro, "Packaging and interconnection technologies of power devices, challenges and future trends", World academy of science, engineering and technology, vol.49, (2009), pp.691694.

[11] D. W. Brown, M. Abbas, A. Ginart, I. N. Ali, P. W. Kalgren and G. J. Vachtsevanos, "Turn-off time as an early indicator of insulated gate bipolar transistor latch-up", Power Electronics, IEEE Transactions on, vol. 27, no. 2, (2012), pp.479-489.

[12] "Military Handbook. Reliability prediction of electronic equipment", USA Department of Defense, MILHDBK-217F Notice, (1991).

[13] P. Ghimire, S. Beczkowski, S. Munk-Nielsen, B.Rannestad and P. B. Thogersen,A" review on real time physical measurement techniques and their attempt to predict wear-out status of IGBT", Power Electronics and Applications (EPE), 2013 15th European Conference on. IEEE, (2013), pp.1-10.

[14] H. Zhang, R. Kang, M. Luo and M. Pecht, "Precursor parameter identification for power supply prognostics and health management", Reliability, Maintainability and Safety. ICRMS 2009. 8th International Conference on. IEEE, (2009), pp.883-887.

[15] B. Ji, X. Song, W. Cao, V. Pickert, Y. Hu, J. W. Mackersie and G. Pierce, "In-Situ Diagnostics and Prognostics of Solder Fatigue in IGBT Modules for Electric Vehicle Drives", Power Electronics, IEEE Transactions on, vol. 30, no. 3, (2015), pp.1535-1543.

[16] V. Smet, F. Forest, J. J. Huselstein, F. Richardeau, Z. Khatir, S. Lefebvre and M. Berkani, "Ageing and failure modes of IGBT modules in high-temperature power cycling", Industrial Electronics, IEEE Transactions on, vol. 58, no. 10, (2011), pp.4931-4941. 
[17] J. M. Anderson, R. W. Cox and P. O'Connor, "Online algorithm for early stage fault detection in IGBT switches", Diagnostics for Electric Machines, Power Electronics and Drives (SDEMPED), 2013 9th IEEE International Symposium on. IEEE, (2013), pp.1-8.

[18] Y. Xiong, X. Cheng, Z. J. Shen, C. Mi, H. Wu and V. K. Garg, "Prognostic and warning system for power-electronic modules in electric, hybrid electric and fuel-cell vehicles", Industrial Electronics, IEEE Transactions on, vol. 55, no. 6, (2008), pp.2268-2276.

[19] V. Smet, F. Forest, J. Huselstein, A. Rashed and F. Richardeau, "Evaluation of Monitoring as a Real-Time Method to Estimate Aging of Bond Wire-IGBT Modules Stressed by Power Cycling", Industrial Electronics, IEEE Transactions on, vol. 60, no. 7, (2013), pp.2760-2770.

[20] M. Tounsi, A. Oukaour, B. Tala-Ighil, H. Gualous, B. Boudart and D. Aissani, "Characterization of high-voltage IGBT module degradations under PWM power cycling test at high ambient temperature", Microelectronics Reliability, vol. 50, no. 9, (2010), pp.1810-1814.

\section{Authors}
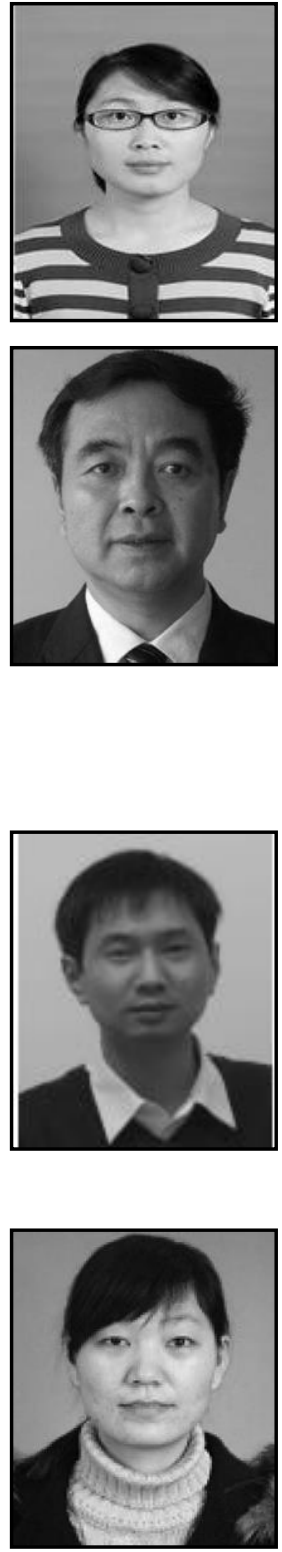

Yaping Li, she received the M.S. degree in College of Mechanical and Electronical Engineering from Shihezi University, Shihezi, China in 2009. She is currently working towards the $\mathrm{PhD}$ degree in electrical engineering at Chongqing University. Her interests include reliability of power electronic module.

Luowei Zhou, he received the B.S., M.S., and Ph.D. degrees in electrical engineering from Chongqing University, Chongqing, China, in 1982, 1988, and 2000, respectively. Since 1982, he has been with the College of University, where he is currently a Full Professor. He was a Visiting Professor with the University of California, Irvine, between September 1998 and August 1999. He is the Vice Director of the China Society of Power Supply. His major fields of interest include the analysis and control of power electronics circuits, realization of active power filters, power factor correction techniques, and high frequency power conversion.

Xiong Du received the B.S., M.S., and Ph.D. degrees from Chongqing University, Chongqing, China in 2000, 2002, and 2005, respectively, all in electrical engineering. Since 2002, he has been with Chongqing University, where he is currently an Associate Professor in the College of Electrical Engineering. From July 2007 to July 2008, he was a visiting Scholar at Rensselaer Polytechnic Institute. His research interests include switching power converters, power quality control, and renewable energy power conversion.

Pengju Sun, she received the B.S. degree in electrical engineering from Chongqing University, Chongqing, China, in 2005, where since September 2005, she has been working toward the Master's/Ph.D. combined degree. Between September 2009 and August 2010, she was a visiting student with the University of California, Irvine. Her research interests include wide output range dc/dc converters, digital control techniques, high-power high-performance power converters, and power factor correction. 


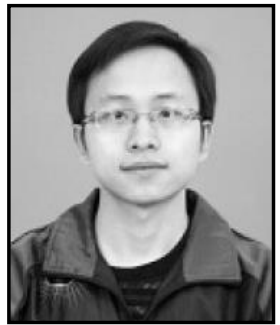

Junke Wu, he received the B.Eng. degree in electrical engineering from Chongqing University, Chongqing, China in 2008, where he is currently pursuing the Ph.D. degree. He was invited to Yuanze University, Taiwan as an exchange student from 2010 to 2011. His research interests include reliability and thermal management of power electronic converters. 
International Journal of Control and Automation Vol. 9, No. 12 (2016) 